\title{
Involvement of Leukotriene Production in Release of Hepatic Lipase Activity Produced by Heparin from Rat Hepatocytes
}

\author{
Hisashi Tagashira, Rie Kerakawati, Toshio Motoyashiki, and Tetsuo Morita* \\ Department of Biochemistry, Faculty of Pharmacy and Pharmaceutical Sciences, Fukuyama University, 985, Higashimura, Fukuyama, \\ Hiroshima 729-0292, Japan
}

(Received November 14, 2005; Accepted November 28, 2005)

Heparin is known to stimulate the release of hepatic lipase (HTGL) activity from hepatocytes, but the action mechanisms have not been fully confirmed. Here, we investigated the involvement of the arachidonate pathway in the heparin-stimulated release of HGTL activity from rat hepatocytes. Heparin increased phospholipase (PL) $\mathrm{A}_{2}$ activity in the hepatocytes in a time- and dose-dependent manner. The stimulatory effect of heparin on PLA $\mathrm{P}_{2}$ activity was markedly decreased by incubation with protein tyrosine kinase (TK) inhibitors. It was also observed that heparin rapidly increased leukotriene (LT) $B_{4}$ and $\mathrm{LTC}_{4} / \mathrm{D}_{4} / \mathrm{E}_{4}$ contents in the hepatocytes. In addition, the stimulatory release of HTGL activity by heparin was suppressed by cytosolic PLA, 5-lipoxygenase and LTA $_{4}$ hydrolase inhibitors, but not by cyclooxygenase and thromboxane (TX) synthetase inhibitors or a TXA receptor antagonist. These findings suggest that the heparin-stimulated release of HTGL activity from hepatocytes is partly due to an action involving increases in cytosolic PLA $\mathrm{A}_{2}$ activity and LTs production with associated of TK activity.

Key words — hepatic lipase, heparin, hepatocyte, phospholipase $\mathrm{A}_{2}$, leukotriene

\section{INTRODUCTION}

Hepatic lipase (hepatic triacylglyceride lipase; HTGL, EC 3.1.1.3), which is involved in different steps in the metabolism of lipoprotein triacylglycerides as a lipase of the vascular compartment, is a lipolytic enzyme primarily synthesized by, and re-

\footnotetext{
*To whom correspondence should be addressed: Department of Biochemistry, Faculty of Pharmacy and Pharmaceutical Sciences, Fukuyama University, 985, Higashimura, Fukuyama, Hiroshima 729-0292, Japan. Tel.: +81-84-936-2111 (Ext. 5221); Fax: +81-84-936-2024; E-mail: morita@fupharm.fukuyamau.ac.jp
}

leased from, hepatocytes. ${ }^{1-3)}$ This enzyme is found to be localized at the surface of endothelial cells, and is anchored to the plasma membrane of endothelial cells by electrostatic interactions with heparan sulfate proteoglycans. ${ }^{4-7)}$ The release of HTGL activity from hepatocytes is well-known for its acceleration by heparin, which is an acidic mucopolysaccharide consisting of $\mathrm{N}$-, $\mathrm{N}$-acetyl, $\mathrm{O}$-sulfonic substituents for D-glucosamine, D-glucuronic acid and iduronic acid that is synthesized in the liver, lungs and most other tissues. ${ }^{6-9)}$ Heparin releases HTGL by direct interaction with the enzyme or by competing for the binding sites on the cell surface. ${ }^{5,6)}$ The mechanism of this action is thought to be due to an interaction with the negative charge of each molecule, but the detailed mechanism has not been confirmed.

Previously, Leslie et al. reported that heparin stimulated phospholipase (PL) $\mathrm{A}_{2}$, which is an enzyme that hydrolyses the $s n-2$ acyl ester bond of phospholipids, generating free fatty acids and lysophospholipids, in a macrophage cytosolic fraction. ${ }^{10)}$ The release of arachidonic acid from membrane phospholipids by $\mathrm{PLA}_{2}$ provides the substrate for the biosynthesis of leukotrienes (LTs) and prostaglandins, which are potent mediators of functions such as vasoactivity and inflammation. ${ }^{11-13)}$ Indeed, Shalit et al. have reported that heparin and heparan sulfate increased the production of $\mathrm{LTB}_{4}$ and $\mathrm{LTC}_{4}$ in cultured mouse E-mast cells. ${ }^{14)}$ Recently, we have also shown that heparin rapidly increased the $\mathrm{LTB}_{4}$ content in cultured rat hepatocytes. ${ }^{15)}$ However, the involvement of PLA $\mathrm{P}_{2}$ and LTs in the heparin-stimulated release of HTGL activity is still unknown.

In this study, we investigated whether the release of HTGL activity from rat cultured hepatocytes by heparin is associated with increases in PLA 2 activity and the production of LTs. 


\section{MATERIALS AND METHODS}

Materials — Glycerol tri[ $\left[1-{ }^{14} \mathrm{C}\right]$ oleate $(2.3 \mathrm{GBq} /$ mmol), L- $\alpha$-1-palmitoyl-2-arachidonyl, [arachidonyl-1-14 $\mathrm{C}$ ]-phosphatidylcholine (1776 MBq/ mmol), the $\mathrm{LTB}_{4}$ enzymeimmunoassay system (RPN223) and the $\mathrm{LTC}_{4} / \mathrm{D}_{4} / \mathrm{E}_{4}$ enzymeimmunoassay system (RPN224) were obtained from Amersham (Tokyo, Japan). Heparin, manoalide, AA-861, indomethacin, aspirin, bestatin, arachidonyl trifluoromethyl ketone $\left(\mathrm{AACOCF}_{3}\right)$ and collagenase were purchased from Wako Pure Chemical Industries (Osaka, Japan). Nordihydroguaiaretic acid (NDGA) was obtained from Funakoshi Co., Ltd. (Tokyo, Japan). ONO-3708 and OKY-046 were provided by Ono Pharmaceutical Co., Ltd. (Osaka, Japan). Biochanin A was obtained from Sigma (MO, U.S.A.). ST-638 was provided by Dr. Tadayoshi Shiraishi (Kanegafuchi Chemical Industry, Osaka, Japan). Williams' medium E was from Gibco (NY, U.S.A.). All other chemicals used were of analytical grade.

\section{Preparation and Incubation of Hepatocytes -} Male Wistar rats, weighing 200-250 g, were fed on a commercial laboratory chow ad libitum and fasted for $24 \mathrm{hr}$ before the experiments. Hepatocytes were isolated by in vitro collagenase perfusion and low speed centrifugation with modifications. ${ }^{16,17)}$ Contamination by Kupffer cells of the hepatocyte preparation was confirmed to be less than $2 \%$ by peroxidase staining. ${ }^{18)}$ Cell viability was determined by trypan blue exclusion and ranged from 85 to $95 \%$. The hepatocytes were cultured for $24 \mathrm{hr}$ in monolayers in plastic dishes $\left(1 \times 10^{5}\right.$ cells $\left./ \mathrm{cm}^{2}\right)$ in Williams' medium E containing $10 \%$ fetal calf serum, $10 \mathrm{nM}$ insulin, $10 \mathrm{nM}$ dexamethasone and $5 \mathrm{kIU} / \mathrm{ml}$ aprotinin under a $5 \% \mathrm{CO}_{2}$ atmosphere. After removal of the medium by aspiration, the monolayers of hepatocytes were further incubated 0-60 min in Williams' medium E containing $2 \%$ bovine serum albumin with or without the addition of heparin. The hepatocytes were harvested and centrifuged at $50 \times g$ for $5 \mathrm{~min}$ to remove cellular debris. The supernatant obtained served as the preparation for assaying the release of HTGL activity.

Determination of HTGL Activity - HTGL activity was determined using glycerol tri $\left[1-{ }^{14} \mathrm{C}\right]-$ oleate $(1.2 \mu \mathrm{M} ; 2.5 \mathrm{kBq} / \mathrm{ml})$ as a substrate. ${ }^{19)}$ The HTGL activity was expressed as pmol of free fatty acid (FFA) produced $/ \mathrm{min} / 10^{6}$ cells.

Determination of PLA $\mathbf{A}_{2}$ Activity $-\mathrm{PLA}_{2}$ activity was determined by the method of Teramoto $e t$ $a l .{ }^{20)}$ Briefly, the incubated hepatocytes were homogenized in $10 \mathrm{mM}$ Tris-HCl buffer ( $\mathrm{pH}$ 7.4) containing $0.25 \mathrm{M}$ sucrose and $0.1 \mathrm{mM} \mathrm{CaCl}_{2}$ by Physcotron (a microhomogenizer; NS-310E model, Niti-on Co., Tokyo, Japan), and were centrifuged at $105000 \times g$ for $60 \mathrm{~min}$ at $4^{\circ} \mathrm{C}$. The supernatant contained the cytosolic and also the membrane fraction. The supernatant was used as the enzyme preparation of $\mathrm{PLA}_{2}$ which hydrolyzed L- $\alpha$-1-palmitoyl-2-[ $\left[{ }^{14} \mathrm{C}\right]$ arachidonyl-phosphatidylcholine as a substrate. ${ }^{10,21)}$ The free fatty acids released were extracted and quantified. The PLA ${ }_{2}$ activity was expressed as pmol/ $\min / 10^{6}$ cells.

Determination of LT Contents - Contents of LTs in hepatocytes which had been incubated with or without heparin were measured. The hepatocytes $\left(0.9 \times 10^{6}\right.$ cells $)$ were homogenized in ice-cold $5 \%$ trichloroacetic acid (TCA), then centrifuged at 6000 $\times g$ for $10 \mathrm{~min}$. The supernatant was extracted with $\mathrm{H}_{2} \mathrm{O}$-saturated diethyl ether to remove TCA. The TCA-soluble fraction was subjected to a quantitative analysis of LT contents using an enzymeimmunoassay with a commercially available LTs-assay system from Amersham. ${ }^{22,23)}$

Data Analysis — In each experiment, results are the mean \pm S.E. of three or four observations for separate experiments using different hepatocyte preparations.

\section{RESULTS}

Figure 1a shows the change in $\mathrm{PLA}_{2}$ activity in hepatocytes incubated with heparin $(2 \mathrm{U} / \mathrm{ml})$ over a 7-min period. A time-dependent increase in $\mathrm{PLA}_{2}$ activity was observed up to $5 \mathrm{~min}$. Next, the hepatocytes were incubated with heparin at different concentrations for $5 \mathrm{~min}$. $\mathrm{PLA}_{2}$ activity increased in a dose-dependent manner up to $3 \mathrm{U} / \mathrm{ml}$ (Fig. 1b).

Recently, we have reported that the release of HTGL activity by heparin from primary cultured rat hepatocytes is associated with the activation of membrane tyrosine kinase (TK). ${ }^{24)}$ Therefore, to determine whether TK is involved in the stimulatory effect on $\mathrm{PLA}_{2}$ activity by heparin, the hepatocytes were incubated with heparin in the presence of two TK inhibitors, biochanin A and ST-638. ${ }^{25,26)}$ The heparin-stimulated increase in PLA $_{2}$ activity was markedly suppressed by both inhibitors (Fig. 2).

Whether the stimulatory release of HTGL activity by heparin is involved in the increase in $\mathrm{PLA}_{2}$ activity was examined. The effects of $\mathrm{PLA}_{2}$ inhibi- 
a)

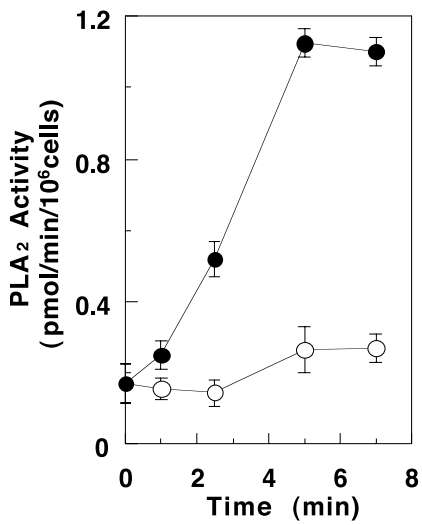

b)

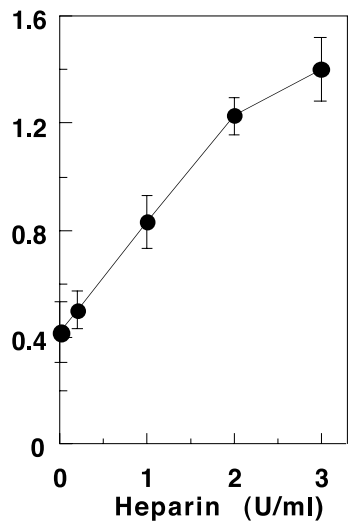

Fig. 1. Effect of Heparin on PLA 2 Activity in Hepatocytes

(a) The hepatocytes were incubated with heparin $(2 \mathrm{U} / \mathrm{ml}, \bullet)$ or without $(\bigcirc)$ over a 7-min period. (b) The hepatocytes were incubated for 5 min with various concentrations $(0-3 \mathrm{U} / \mathrm{ml})$ of heparin. PLA $_{2}$ activity was measured as described in MATERIALS AND METHODS. a)

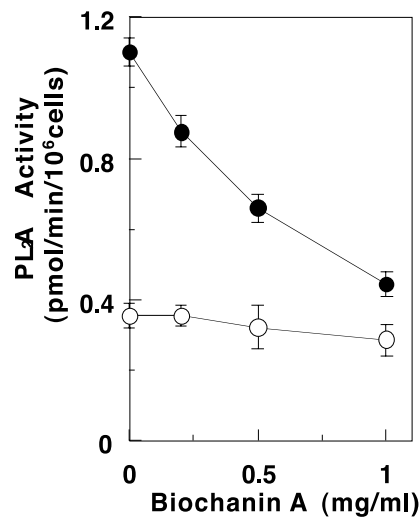

b)

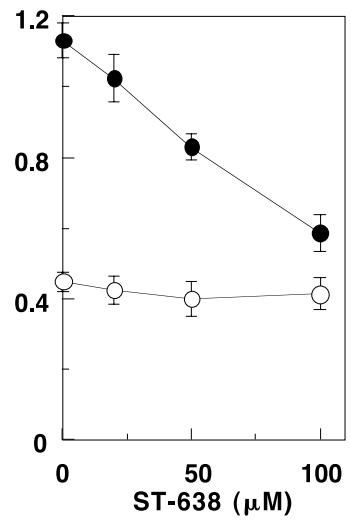

Fig. 2. Effects of TK Inhibitors on the Increase in $\mathrm{PLA}_{2}$ Activity Caused by Heparin

(a) The hepatocytes were incubated with heparin $(2 \mathrm{U} / \mathrm{ml}, 0)$ or without $(O)$ in the presence of biochanin A. (b) The hepatocytes were incubated with heparin $(2 \mathrm{U} / \mathrm{ml}, \bullet)$ or without $(O)$ in the presence of ST-638. PLA A $_{2}$ activity was measured as described in MATERIALS AND METHODS

tors, such as $\mathrm{AACOCF}_{3}$ (a specific cytosolic $\mathrm{PLA}_{2}$ inhibitor) and manoalide (a weakly specific cytosolic and/or secretory PLA $\mathrm{P}_{2}$ inhibitor), on the release of HTGL activity by heparin are shown in Fig. 3.27,28) The stimulatory effect of heparin was reduced more by $\mathrm{AACOCF}_{3}$ than manoalide.

To determine whether the mechanism of the heparin-stimulated release of HTGL activity affects the LTs contents in hepatocytes, the hepatocytes were incubated with heparin for 5 and $15 \mathrm{~min}$. When the hepatocytes were incubated with various concentra- a)

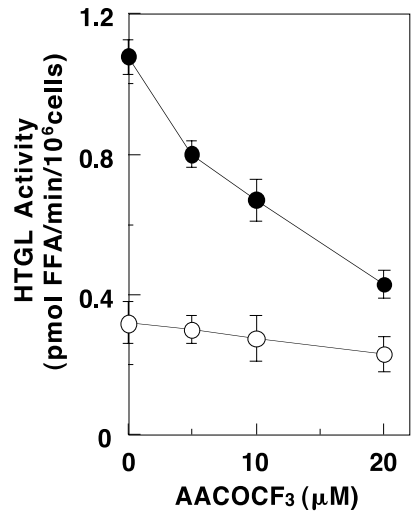

b)

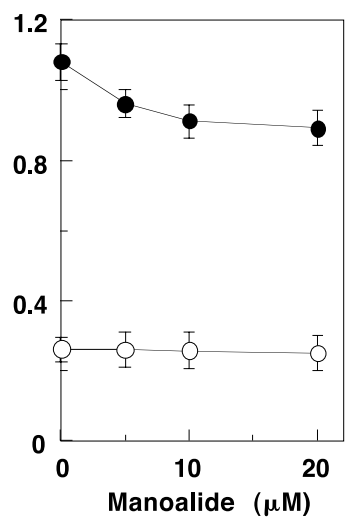

Fig. 3. Effects of $\mathrm{PLA}_{2}$ Inhibitors on the Release of HTGL Activity by Heparin

(a) The hepatocytes were incubated with heparin $(2 \mathrm{U} / \mathrm{ml}, \mathbf{O})$ or without $(\mathrm{O})$ in the presence of $\mathrm{AACOCF}_{3}$. (b) The hepatocytes were incubated with heparin $(2 \mathrm{U} / \mathrm{ml}, 0)$ or without $(\bigcirc)$ in the presence of manoalide. The activity of HTGL released into the medium was measured as described in MATERIALS AND METHODS.

a)

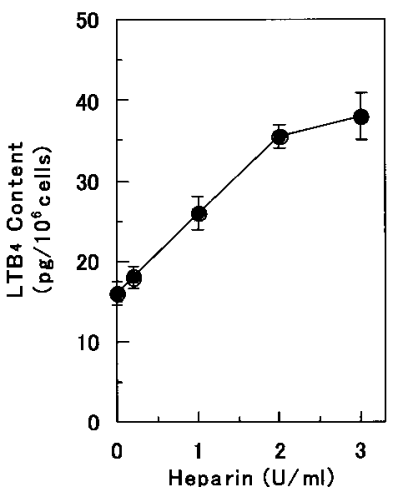

b)

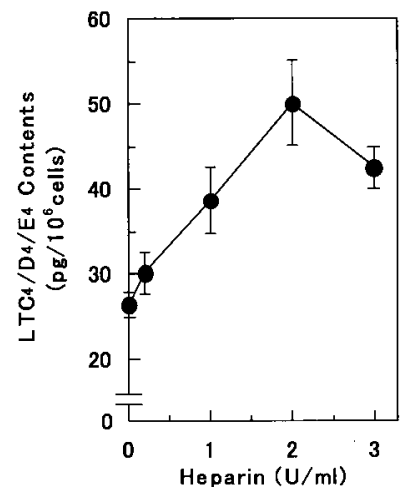

Fig. 4. Increase in LTs Contents in Hepatocytes Caused by Heparin

The hepatocytes were incubated with various concentrations $(0-$ $3 \mathrm{U} / \mathrm{ml}$ ) of heparin for 5 and $15 \mathrm{~min}$ to measure the $\mathrm{LTB}_{4}$ (a) and $\mathrm{LTC}_{4} /$ $\mathrm{D}_{4} / \mathrm{E}_{4}$ contents (b), respectively. The LTs contents in the hepatocytes were determined as described in MATERIALS AND METHODS.

tions of heparin, $\mathrm{LTB}_{4}$ and $\mathrm{LTC}_{4} / \mathrm{D}_{4} \mathrm{E}_{4}$ contents increased in a dose-dependent manner up to 3 and $2 \mathrm{U} / \mathrm{ml}$ of heparin, respectively (Fig. 4).

In addition, we investigated the effects of various modulators of eicosanoid production on the release of HTGL activity by heparin (Table 1). The heparin-stimulated release of HTGL activity was markedly suppressed by a widely specific 5-lipoxygenase (LPO) inhibitor, NDGA and a specific 5-LPO inhibitor, AA-861, and an $\mathrm{LTA}_{4}$ hydrolase inhibitor, bestatin. ${ }^{29-31)}$ In contrast, cyclooxygenase inhibitors, 
Table 1. Effects of Various Chemicals on the Release of HTGL Activity by Heparin

\begin{tabular}{lcc}
\hline \hline Chemicals & & Relative HTGL Activity (\%) \\
\hline None & & 100 \\
NDGA & $(25 \mu \mathrm{M})$ & $72.3 \pm 1.8$ \\
& $(50 \mu \mathrm{M})$ & $43.5 \pm 3.1$ \\
AA-861 & $(25 \mu \mathrm{M})$ & $53.0 \pm 2.9$ \\
& $(50 \mu \mathrm{M})$ & $15.2 \pm 2.1$ \\
Bestatin & $(25 \mu \mathrm{M})$ & $71.6 \pm 3.2$ \\
& $(50 \mu \mathrm{M})$ & $59.8 \pm 2.2$ \\
Indomethacin & $(50 \mu \mathrm{M})$ & $106.5 \pm 3.1$ \\
& $(200 \mu \mathrm{M})$ & $106.3 \pm 4.3$ \\
Aspirin & $(50 \mu \mathrm{M})$ & $99.9 \pm 1.5$ \\
& $(200 \mu \mathrm{M})$ & $101.5 \pm 2.7$ \\
OKY-046 & $(25 \mu \mathrm{M})$ & $105.8 \pm 0.2$ \\
ONO-3708 & $(50 \mu \mathrm{M})$ & $93.1 \pm 3.4$ \\
& $(25 \mu \mathrm{M})$ & $96.0 \pm 2.1$ \\
& $(50 \mu \mathrm{M})$ & $96.4 \pm 2.7$
\end{tabular}

The hepatocytes were incubated for $60 \mathrm{~min}$ with or without heparin $(2 \mathrm{U} / \mathrm{ml})$ in the presence of various agents, as described in MATERIALS AND METHODS. No significant change in basal HTGL activity was found with any inhibitor alone. Percentage values were calculated from net activity.

such as indomethacin and aspirin, a thromboxane (TX) synthetase inhibitor, OKY-046, and a TXA 2 receptor antagonist, ONO-3708 did not suppress the release of HTGL activity by heparin. ${ }^{32-35)}$

\section{DISCUSSION}

Recently, we have reported that the release of HTGL activity from cultured rat hepatocytes by heparin is associated with the activation of membrane TK. ${ }^{24)}$ However, the action mechanisms of the heparin-stimulated release of HTGL activity are still unclear. Here, we further investigated the stimulatory effects of heparin on the release of HTGL activity. It was observed that $\mathrm{PLA}_{2}$ activity in hepatocytes incubated with heparin increased, and that the heparin-stimulated release of HTGL activity was markedly suppressed by a specific cytosolic $\mathrm{PLA}_{2}$ inhibitor, $\mathrm{AACOCF}_{3}$. These findings suggest that the stimulatory release of HTGL activity by heparin may be closely involved with the increase in cytosolic $\mathrm{PLA}_{2}$ activity. In addition, the stimulatory increase in $\mathrm{PLA}_{2}$ activity by heparin was thought to be sensitive to membrane TK activity from our results. According to one report, cytosolic $\mathrm{PLA}_{2}$ is phosphorylated at serine 505 by mitogen-activated protein kinase, and then activated. ${ }^{36)}$ Goldberg et al. found that
$\mathrm{PLA}_{2}$ is also stimulated by TKs of the growth factor-activated receptor. ${ }^{37)}$ In this study, it is possible that the activation of membrane TK by heparin caused an increase in $\mathrm{PLA}_{2}$ activity. The details, however, remain to be elucidated. Also, cytosolic $\mathrm{PLA}_{2}$ plays an important role in the separation of arachidonate from membrane phospholipids, and the arachidonate produced is converted to LTs by 5LPO. ${ }^{12)}$ We found that the heparin-stimulated release of HTGL activity was suppressed by 5-LPO and $\mathrm{LTA}_{4}$ hydrolase inhibitors, and that the $\mathrm{LTB}_{4}$ and $\mathrm{LTC}_{4} / \mathrm{D}_{4} / \mathrm{E}_{4}$ contents in hepatocytes incubated with heparin rapidly increased. These results suggest that the heparin-stimulated release of HTGL activity occurs via an LTs-sensitive process. It has been reported that epidermal growth factor, the receptor of which has TK activity, stimulates production of $\mathrm{LTC}_{4}$ in P19 8-39 cells. ${ }^{38)}$ According to Yokomizo et al., the activation of 5-LPO caused by a receptor-mediated agonist in neutrophils is due to an elevation of the intracellular $\mathrm{Ca}^{2+}$ concentration and activation of TK. ${ }^{39)}$ Activation of the membrane TK by heparin in cultured rat hepatocytes was also reported to cause an increase in the intracellular $\mathrm{LTB}_{4}$ contents. ${ }^{15)}$

In conclusion, our results suggest that the stimulatory release of HTGL activity by heparin is, in part, caused through a pathway involving an increase in $\mathrm{PLA}_{2}$ activity and the resulting rise in LTs contents and an association with TK activity on the cell membrane.

\section{REFERENCES}

1) Nilsson-Ehle, P., Garfinkel, A. S. and Schotz, M. C. (1980) Lipolytic enzymes and plasma lipoprotein metabolism. Annu. Rev. Biochem., 49, 667-693.

2) Laposata, E. A., Laboda, H. M., Glick, J. M. and Strauss, J. F. (1987) Hepatic lipase. J. Biol. Chem., 262, 5333-5338.

3) Connelly, P. W. and Hegele, R. A. (1998) Hepatic lipase deficiency. Crit. Rev. Clin. Lab. Sci., 35, 547572.

4) LaRosa, J. C., Levy, R. I., Windmueller, H. G. and Fredrickson, D. S. (1972) Comparison of the triglyceride lipase of liver, adipose tissue, and postheparin plasma. J. Lipid Res., 13, 356-363.

5) Assmann, G., Krauss, R. M., Fredrickson, D. S. and Levy, R. I. (1973) Characterization, subcellular localization, and partial purification of a heparin-released triglyceride lipase from rat liver. J. Biol. Chem., 248, 1992-1999.

6) Kuusi, T., Nikkila, E. A., Virtanen, I. and Kinnunen, 
P. K. J. (1979) Localization of the heparin-releasable lipase in situ in the rat liver. Biochem. J., 181, 245-246.

7) Jackson, R. L. and McLean, L. R. (1991) Human postheparin plasma lipoprotein lipase and hepatic triglyceride lipase. Methods Enzymol., 197, 339345.

8) Ehrlich, J. and Stivala, S. S. (1973) Chemistry and pharmacology of heparin. J. Pharm. Sci., 62, 517544.

9) Ragazzi, E. and Chinellato, A. (1995) Heparin: pharmacological potentials from atherosclerosis to asthma. Gen. Pharmacol., 26, 697-701.

10) Leslie, C. C., Voelker, D. R., Channon, J. Y., Wall, M. M. and Zelarney, P. T. (1988) Properties and purification of an arachidonoyl-hydrolyzing phospholipase $\mathrm{A}_{2}$ from a macrophage cell line, RAW 264.7. Biochim. Biophys. Acta, 963, 476-492.

11) Kudo, I., Murakami, M., Hara, S. and Inoue, K. (1993) Mammalian non-pancreatic phospholipase $\mathrm{A}_{2}$. Biochim. Biophys. Acta, 1170, 217-231.

12) Samuelsson, B. (1983) Leukotrienes: mediators of immediate hypersensitivity reactions and inflammation. Science, 220, 568-575.

13) Hammarstrom, S. (1983) Leukotrienes. Annu. Rev. Biochem., 52, 355-377.

14) Shalit, M., Shoam, H., Seno, N. and Razin, E. (1986) New role for heparan sulfate: regulator of leukotriene generation in mouse E-mast cells. Life Sci., 39, 903910.

15) Tagashira, H., Kerakawati, R., Motoyashiki, T. and Morita, T. (2005) Rapid increase in the leukotriene $\mathrm{B}_{4}$ concentration of cultured rat hepatocytes by heparin. J. Health Sci., 51, 510-513.

16) Berry, M. N. and Friend, D. S. (1964) High-yield preparation of isolated rat liver parenchymal cells. J. Cell Biol., 43, 506-520.

17) Mori, M., Morita, T., Ikeda, F., Amaya, Y., Tatibana, M. and Cohen, P. P. (1981) Synthesis, intracellular transport, and processing of the precursors for mitochondrial ornithine transcarbamylase and carbamoyl-phosphate synthetase I in isolated hepatocytes. Proc. Natl. Acad. Sci. U.S.A., 78, 6056-6060.

18) Wisse, E. (1974) Observations on the fine structure and peroxidase cytochemistry of normal rat liver Kupffer cells. J. Ultrastruct. Res., 46, 393-426.

19) Schotz, M. C., Garfinkel, A. S., Huebotter, R. J. and Stewart, J. E. (1970) A rapid assay for lipoprotein lipase. J. Lipid Res., 11, 68-69.

20) Teramoto, T., Tojo, H., Yamano, T. and Okamoto, M. (1983) Purification and some properties of rat spleen phospholipase $\mathrm{A}_{2}$. J. Biochem., 93, 1353 1360.

21) Murakami, M., Matsumoto, R., Urade, Y., Austen,
K. F. and Arm, J. P. (1995) c-Kit ligand mediates increased expression of cytosolic phospholipase $\mathrm{A}_{2}$, prostaglandin endoperoxide synthase- 1 , and hematopoietic prostaglandin $\mathrm{D}_{2}$ synthase and increased IgEdependent prostaglandin $\mathrm{D}_{2}$ generation in immature mouse mast cells. J. Biol. Chem., 270, 3239-3246.

22) Murakami, N., Aihara, S., Iwata, K., Saito, T. and Naruse, T. (1999) Effect of a novel non-steroidal anti-inflammatory drug (M-5011) on cytokine levels in rats with monosodium urate crystal-induced pleurisy. Jpn. J. Pharmacol., 79, 439-446.

23) Yoo, M. H., Woo, C. H., You, H. J., Cho, S. H., Kim, B. C., Choi, J. E., Chun, J. S., Jhun, B. H., Kim, T. S. and Kim, J. H. (2001) Role of the cytosolic phospholipase $\mathrm{A}_{2}$-linked cascade in signaling by an oncogenic, constitutively active Ha-Ras isoform. $J$. Biol. Chem., 276, 24645-24653.

24) Tagashira, H., Nakahigashi, S., Kerakawati, R., Motoyashiki, T. and Morita, T. (2005) Involvement of $\mathrm{Ca}^{2+} /$ calmodulin-dependent protein kinase II in heparin-stimulated release of hepatic lipase activity from rat hepatocytes. Biol. Pharm. Bull., 28, 409412.

25) Geahlen, R. L., Koonchanok, N. M., Mclaughlin, J. L. and Pratt, D. E. (1989) Inhibition of protein-tyrosine kinase activity by flavanoids and related compounds. J. Nat. Prod., 52, 982-986.

26) Shiraishi, T., Domoto, T., Imai, N., Shimada, Y. and Watanabe, K. (1987) Specific inhibitors of tyrosinespecific protein kinase, synthetic 4-hydroxycinnamamide derivatives. Biochem. Biophys. Res. Commun., 147, 322-328.

27) Bartoli, F., Lin, H. K., Ghomashchi, F., Gelb, M. H., Jain, M. K. and Apitz-Castro, R. (1994) Tight binding inhibitors of $85-\mathrm{kDa}$ phospholipase $\mathrm{A}_{2}$ but not 14-kDa phospholipase $A_{2}$ inhibit release of free arachidonate in thrombin-stimulated human platelets. J. Biol. Chem., 269, 15625-15630.

28) Husain, S. and Abdel-Latif, A. A. (1998) Role of protein kinase $\mathrm{C}$ alpha in endothelin-1 stimulation of cytosolic phospholipase $\mathrm{A}_{2}$ and arachidonic acid release in cultured cat iris sphincter smooth muscle cells. Biochim. Biophys. Acta, 1392, 127-144.

29) Wang, Y., Zhou, B., Li, J., Cao, Y. B., Chen, X. S., Cheng, M. H. and Yin, M. (2004) Inhibition of 5lipoxygenase inhibit expression of intercellular adhesion molecule-1 in human melanoma cells. Acta Pharmacol. Sin., 25, 672-677.

30) Yoshimoto, T., Yokoyama, C., Ochi, K., Yamamoto, S., Maki, Y., Ashida, Y., Terao, S. and Shiraishi, M. (1982) 2,3,5-Trimethyl-6-(12-hydroxy-5,10-dodecadiynyl)-1,4-benzoquinone (AA861), a selective inhibitor of the 5-lipoxygenase reaction and the biosynthesis of slow-reacting substance of anaphylaxis. 
Biochim. Biophys. Acta, 713, 470-473.

31) Orning, L., Krivi, G. and Fitzpatrick, F. A. (1991) Leukotriene $\mathrm{A}_{4}$ hydrolase. Inhibition by bestatin and intrinsic aminopeptidase activity establish its functional resemblance to metallohydrolase enzymes. $J$. Biol. Chem., 266, 1375-1378.

32) Roth, G. J., Stanford, N. and Majerus, P. W. (1975) Acetylation of prostaglandin synthase by aspirin. Proc. Natl. Acad. Sci. U.S.A., 72, 3073-3076.

33) Stanford, N., Roth, G. J., Shen, T. Y. and Majerus, P. W. (1977) Lack of covalent modification of prostaglandin synthetase (cyclo-oxygenase) by indomethacin. Prostaglandins, 13, 669-675.

34) Naito, J., Komatsu, H., Ujiie, A., Hamano, S., Kubota, T. and Tsuboshima, M. (1983) Effects of thromboxane synthetase inhibitors on aggregation of rabbit platelets. Eur. J. Pharmacol., 91, 41-48.

35) Kondo, K., Seo, R., Omawari, N., Imawaka, H., Wakitani, K., Kira, H., Okegawa, T. and Kawasaki, A. (1989) Effects of ONO-3708, an antagonist of the thromboxane $\mathrm{A}_{2}$ /prostaglandin endoperoxide receptor, on blood vessels. Eur. J. Pharmacol., 168, 193-200.

36) Lin, L. L., Wartmann, M., Lin, A. Y., Knopf, J. L., Seth, A. and Davis, R. J. (1993) cPLA 2 is phosphorylated and activated by MAP kinase. Cell, 72, 269278.

37) Goldberg, H. J., Viegas, M. M., Margolis, B. L., Schlessinger, J. and Skorecki, K. L. (1990) The tyrosine kinase activity of the epidermal-growth-factor receptor is necessary for phospholipase $\mathrm{A}_{2}$ activation. Biochem. J., 267, 461-465.

38) Peppelenbosch, M. P., Tertoolen, L. G. J., Den Hertog, J. and De Laat, S. W. (1992) Epidermal growth factor activates calcium channels by phospholipase $\mathrm{A}_{2} / 5$-lipoxygenase-mediated leukotriene $\mathrm{C}_{4}$ production. Cell, 69, 295-303.

39) Yokomizo, T., Izumi, T. and Shimizu, T. (2001) Leukotriene $\mathrm{B}_{4}$ : metabolism and signal transduction. Arch. Biochem. Biophys., 385, 231-241. 